\title{
Genetic causes of hypopituitarism
}

Katherine Parkin ${ }^{1}$, Ritika Kapoor ${ }^{2}$, Ravindra Bhat ${ }^{3,4}$, Anne Greenough ${ }^{4,5,6}$

\author{
${ }^{1}$ King's College London, Guy's King's and St Thomas School of Medicine, London, \\ United Kingdom \\ 2Department of Paediatric Endocrinology, King's College Hospital NHS Foundation \\ Trust, London, United Kingdom \\ ${ }^{3}$ Neonatal Intensive Care Centre, King's College Hospital NHS Foundation Trust, \\ London, United Kingdom \\ ${ }^{4}$ Department of Women and Children's Health, School of Life Course Sciences, \\ Faculty of Life Sciences and Medicine, King's College London, United Kingdom \\ ${ }^{5}$ Asthma UK Centre in Allergic Mechanisms of Asthma, King's College London, \\ United Kingdom \\ ${ }^{6}$ NIHR Biomedical Research Centre based at Guy's and St Thomas' NHS Foundation \\ Trust and King's College London, United Kingdom
}

Submitted: 10 December 2018

Accepted: 24 March 2019

Arch Med Sci 2020; 16 (1): 27-33

DOI: https://doi.org/10.5114/aoms.2020.91285

Copyright (c) 2019 Termedia \& Banach

\begin{abstract}
Hypopituitarism in neonates is rare, but has life-threatening complications if untreated. This review describes the features of hypopituitarism and the evidence for which infants in whom a genetic cause should be suspected. Importantly, neonates are often asymptomatic or present with non-specific symptoms. Hypopituitarism can be due to abnormal gland development as a result of genetic defects, which result from mutations in gene coding for transcription factors which regulate pituitary development. The mutations can be divided into those causing isolated hypopituitarism or those causing syndromes with associated hypopituitarism. The latter involve mutations in transcription factors which regulate pituitary, as well as extra-pituitary development. There is a paucity of evidence as to which patients should be investigated for genetic mutations, but detailed clinical and biochemical phenotyping with magnetic resonance imaging of the pituitary gland could help target those in whom genetic investigations would be most appropriate.
\end{abstract}

Key words: congenital hypopituitarism; genetic defects, magnetic resonance imaging.

\section{Introduction}

Hypopituitarism in neonates is rare. It affects between 1 in 4000 to 1 in 10,000 live births [1] and can manifest as a partial or complete insufficiency of pituitary hormone secretion. It is, however, a serious condition with life-threatening complications if untreated. Although $52 \%$ of neonates with hypopituitarism present postnatally with associated complications, only $23 \%$ are diagnosed in the neonatal period [2]. Neonates are often asymptomatic or present with non-specific symptoms. This review focuses on the genetic causes of hypopituitarism including those causing isolated pituitary problems and those with extra-pituitary manifestations and assesses the evidence base to determine which infants in whom a genetic cause should be suspected and investigated.
Corresponding author:

Prof. Anne Greenough

Women and

Children's Health

School of Life

Course Sciences

Faculty of Life

Sciences and Medicine

Kings College London

Denmark Hill, SE5 9RS

London, United Kingdom

Phone: +44203 2993037

E-mail: anne.greenough@kcl. ac.uk 


\section{Presentation}

Congenital hypopituitarism may present with a loss of function of a single pituitary hormone, commonly isolated growth hormone deficiency (IGHD), or with two or more pituitary hormone deficiencies (multiple pituitary hormone deficiency MPHD). It may be part of an underlying syndrome with abnormalities of extra-pituitary structures such as the eyes and forebrain which have a common embryological origin to the pituitary gland. Neonates may often be asymptomatic and then develop abnormal signs due to evolving hormone deficiencies. Congenital hypopituitarism may present at birth, but is difficult to diagnose in the neonatal period, as the signs may be non-specific, including lethargy, apnoea, poor weight gain and feeding problems and the clinical presentation depends on the pituitary hormone deficiencies present.

Growth failure due to GHD usually presents after the first year after birth, though may be

Table I. Transcription factors related to pituitary development

\begin{tabular}{|c|c|}
\hline HESX1 & $\begin{array}{c}\text { Homeobox expressed in embryonic } \\
\text { stem cells } 1\end{array}$ \\
\hline SOX $2 / \mathrm{SO} 3$ & Sex determining region $\mathrm{Y}$ box $2 / 3$ \\
\hline LHX3, LHX4 & LIM/homeobox protein \\
\hline PROP1 & Homeobox protein prophet of PIT1 \\
\hline POU1F1 & $\begin{array}{l}\text { Pituitary specific positive } \\
\text { transcription factor } 1\end{array}$ \\
\hline PITX & Paired-like homeodomain 1 \\
\hline GLI3, GLI2 & Zinc finger protein \\
\hline OTX2 & Orthodenticle homeobox 2 \\
\hline ARNT2 & $\begin{array}{c}\text { Aryl hydrocarbon receptor nuclear } \\
\text { translocator } 2\end{array}$ \\
\hline IGSF1 & Immunoglobulin superfamily 1 \\
\hline FGF8 & Fibroblast growth factor 8 \\
\hline FGFR1 & Fibroblast growth factor receptor 1 \\
\hline PROKR2, PROK2 & Prokineticin receptor 2 \\
\hline CHD7 & $\begin{array}{l}\text { Chromodomain helicase DNA } \\
\text { binding protein } 7\end{array}$ \\
\hline WDR11 & WD repeat containing protein 11 \\
\hline NFKB2 & Nuclear factor NFкB p100 subunit \\
\hline TCF7L1) & Transcription factor 7 like 1 \\
\hline PAX6 & Paired box protein pax 6 \\
\hline IFT72 & Intraflagellar transport 72 \\
\hline GPR161 & G protein coupled receptor 161 \\
\hline CDON & $\begin{array}{l}\text { Cell adhesion molecule related/ } \\
\text { down regulated by oncogenes }\end{array}$ \\
\hline
\end{tabular}

present in infancy in severe GHD [3]. Severe hypoglycaemia, at or soon after birth, is a uncommon presentation and results from adrenocorticotropic (ACTH) deficiency or lack of growth hormone $(\mathrm{GH})$ secretion [4]. Micropenis, defined as a stretched penis length of less than $2.5 \mathrm{~cm}$, may be present and is caused by low luteinizing hormone $(\mathrm{LH})$ secretion which is responsible for maintaining fetal testosterone production. Bilateral undescended testis may also be present as the fetal testicular descent is dependent on LH. Less specific signs of hypopituitarism include neonatal hepatitis and cholestatic jaundice [5]. In one study, jaundice was found to be the most common presentation in $35 \%$ of those presenting with hypopituitarism as neonates or young infants [6]. The pathophysiology of liver damage in hypopituitarism is suggested to be due to insufficient glucocorticoid and thyroid hormones [7]. In patients with thyroid stimulating hormone (TSH) deficiency, hyperbilirubinaemia can be associated with temperature instability [8]. The most common electrolyte imbalance is hyponatraemia, which is related to inadequate levels of ACTH and TSH. In those with posterior pituitary abnormalities, diabetes insipidus is often the key presentation, due to lack of antidiuretic hormone (ADH).

\section{Genetic abnormalities}

Mutations in any of the genes involved in pituitary development may result in congenital hypopituitarism leading to deficiency in one or more pituitary hormones. Genetic abnormalities, however, are only identified in $5-10 \%$ of those with congenital hypopituitarism, but it is estimated that a further $5-30 \%$ of individuals with a first-degree relative with the disorder possess a genetic mutation yet to be identified [8]. Mutations in gene coding for growth hormone (GH1) and gene coding the growth hormone releasing hormone receptor (GHRHR) are known to cause idiopathic growth hormone deficiency (IGHD). Mutations in various genes which encode transcription factors related to pituitary development have been associated with varying degrees of hypopituitarism (Table I). In one study, $13 \%$ of individuals had a mutation in one of five commonly mutated genes (POU1F1, PROP1, LHX3, LHX4, and HESX1), rising to $52 \%$ of individuals in familial cases of multiple pituitary hormone deficiency (MPHD) [9]. The prevalence of genetic mutations varies worldwide, such that PROP1 mutations account for the majority of genetic MPHD in Europe, but are much less common in Asians [10]. We have focused on the role of the main transcription factors involved in pituitary development and mechanisms underlying hypopituitarism and accompanying phenotypes. 


\section{PROP1}

PROP1, located on chromosome $5 q$, encodes for a paired-like homeodomain protein essential for HESX1 repression and POU1F1 expression [10, 11]. It is essential for the development of most types of anterior pituitary cells, therefore, patients can present with deficiency of all hormones secreted by the anterior pituitary [3]. In humans, at least 25 mutations in PROP1 (both homo- and heterozygous) have been described and these are responsible for the majority of MPHDs [12]. The most frequent mutations are a two-base-pair deletion within exon 2 , causing a frameshift in codon 101 (301-302delAG) and a one-base-pair deletion in codon 50 (150delA). Both result in the production of a termination codon and early cessation of protein sequencing $[10,11]$. Mis-, nonsense and splicing error mutations have also been found [10]. Recessive PROP1 mutations often present with $\mathrm{GH}$ deficiency early in life and may have the phenotypic presentation of gonadotrophin deficiency (micropenis, cryptorchidism, lack of puberty and/or infertility). TSH and ACTH are often normal in early life, but deficiencies in these hormones often evolve with increasing age emphasising the need for continuous monitoring.

\section{POU1F1}

POU1F1 is another pituitary-specific transcription factor, responsible for differentiation of somato-lactotrophs and thyrotophs. These cells secrete $\mathrm{GH}, \mathrm{PRL}$ and TSH. POU1F1 may also be involved in autoregulation of expression, as its binding sites have been found on the POU1F1 gene. Approximately $8 \%$ of MPHD and isolated GH cases are due to mutations in this gene [13]. Since first being described, 38 mutations have been reported; most are autosomal recessive, although five dominant mutations have been found [11, 14, 15]. A sibling case suggests that isolated mutations in the short isoform of POU1F1 might be sufficient for induction of POU1F1 related combined pituitary hormone deficiency [16]. As in PROP1 mutations, individuals may present with $\mathrm{GH}$ deficiency including early growth failure and failure to thrive. The age at presentation of TSH deficiency is highly variable $[14,17]$ and cases with normal TSH levels have been reported [13]. Indeed, the pituitary gland may be normal or hypoplastic on MRI $[11,13]$.

\section{LHX3 and LHX4}

LHX3 and LHX4 are involved in the complex genetic cascade resulting in pituitary development, critical for development of Rathke's pouch. LHX4 is essential for pituitary development and motor neuron specification in mammals [18]. Extra-pituitary expression has been documented in other regions of the brain and spinal cord. Mutations in genes encoding for these transcription factors are rare. Seven different mutations in LHX3, including base pair deletions, mutations and even one case of whole gene deletion have been documented [19]. Mutations in LHX3 present similarly to mutations in PROP1 with GH, PRL, TSH and/or LH/FSH deficiency. Rarely, ACTH deficiency has also been described. In addition to pituitary abnormalities, patients present with a short, rigid cervical spine, limited head rotation and trunk movement [14, 19]. Bilateral sensorineural hearing loss has also been documented in some cases [19]. Other abnormalities include cervical vertebral malformations (rigid neck, scoliosis), mild developmental delay and moderate sensorineural hearing loss [20]. Heterozygous LHX3 mutations may lead to a mild phenotype of combined pituitary hormone deficiency [21]. Sonic hedgehog $(\mathrm{SHH})$ is an essential morphogenetic signal which dictates cell fate decision in several organs in mammals. In vitro data suggest that $\mathrm{SHH}$ is required to specify $\mathrm{LHX3}^{+} / \mathrm{LHX}^{+}$Rathe's Pouch (RP) progenitor identity. In mouse embryos, conditional deletion of $\mathrm{SHH}$ in the anterior hypothalamus results in a fully penetrant phenotype characterised by complete arrest of RP development with lack of LHX3/LHX4 expression and total loss of pituitary development [22]. In one case of LHX4 mutation, a fully penetrant, dominant mutation caused defective splicing. An magnetic resonance imaging (MRI) showed anterior pituitary hypoplasia, an ectopic posterior pituitary and a shortened pituitary stalk. The three-generation family all presented with short stature, some with an abnormal sella turcica and Chiari malformation with pointed cerebellar tonsils [23]. In another case, who presented with severe respiratory distress and hypoglycaemia soon after birth, had multiple pituitary hormone deficiencies. MRI demonstrated a hypoplastic anterior pituitary, an ectopic posterior lobe, a poorly developed sella turcica and Chiari malformation. Sequence analyses of the LHX4 gene identified a heterozygous missense mutation (P366T) in exon 6, which was present in the LIM4 specific domain [18]. Screening of 136 patients with congenital hypopituitarism associated with malformations of brain structures, pituitary stalk or posterior pituitary gland demonstrated a novel dysfunctional LHX4 mutation (p.Thr99fs) which was responsible for the patient's phenotype [24]. In another study, heterozygous missense mutations in LHX4 resulting in the substitution of amino acids resulted in $\mathrm{GH}$ deficiency, +/- reductions in $\mathrm{LH}, \mathrm{TSH}, \mathrm{FSH}$ or ACTH and aberrant pituitary morphology [25]. Screening of 417 unrelated patients with isolated growth hormone deficiency or combined protein deficiency associ- 
ated with ectopic posterior pituitary and/or sella turcica anomalies demonstrated seven heterozygous variations in LHX4 [26].

\section{Homeobox expressed in ES cells 1 (HESX1) and sry-type HMG box (SOX) genes in septo-optic dysplasia}

Septo-optic dysplasia, although rare, is the most common congenital cause of hypopituitarism, encompassing any combination of two of the triad: optic nerve hypoplasia, hypopituitarism and midline structural abnormalities [1]. Its incidence is reported to be 1 in 10,000 live births. Hypopituitarism affects $62 \%$ of those with the condition and its severity may be predicted by the degree of midline structural abnormalities. Several genetic mutations have been demonstrated to result in various forms of the condition [27].

HESX1, a transcriptional repressor, regulates some of the earliest stages of pituitary development. It is expressed during gastrulation in the region which develops into the forebrain, after which it is restricted to expression in the ventral diencephalon and the region of the oral ectoderm which forms Rathke's pouch [14]. It has a role in optic nerve formation [3, 14]. Null HESX1 mice have pituitary hypoplasia, micro- or anophthalmia and agenesis of midline forebrain derivatives; a similar phenotype to that of the human condition septo-optic dysplasia $[14,28]$. A large study confirmed that the overall expression of HESX1 mutations in SOD is low $[9,29]$. Another study looked at the prevalence of pituitary hormone abnormalities with optic nerve hypoplasia (with or without midline brain abnormalities), however, found that the prevalence may be as high as $72 \%$ [30]. Several different mutations have been documented; which vary in the extent of hormone deficiency [14]. Isolated GH deficiency to MPHD have been described with or without optic nerve hypoplasia and or mid-line brain abnormalities $[14,31]$. Heterozygous mutations are milder than the bi-allelic type.

SOX2 and -3 are SRY-related HMG box transcription factors may be responsible for maintaining pituitary progenitor cells and their function [12]. Heterozygous mutations in SOX2 genes are associated with developmental eye abnormalities such as anophthalmia and microphthalmia. Oesophageal abnormalities, urogenital defects, developmental delay and sensorineural hearing loss have also been associated with SOX2 mutations, as SOX2 plays an important role in the development of the eye, forebrain, gastrointestinal tract and urogenital systems. The phenotype usually includes anterior pituitary hypoplasia on MRI scan and hypogonadotrophic hypogonadism. GHD has been described in a single case [32]. SOX3 is lo- cated on the $\mathrm{X}$-chromosome, therefore, mutations in SOX3 primarily affect males. Under and over exposure of the gene has been involved in causing X-linked hypopituitarism, resulting in varying degrees of hypopituitarism, mid-line brain abnormalities and learning disabilities

\section{SHH and GLI2 in holoprosencephaly (HPE)}

HPE encompasses a number of structural midline forebrain abnormalities, some of which are fatal in utero. The most severe form is alobar HPE, whereby the forebrain fails to develop into two hemispheres. This is often accompanied by midline facial deformities. The milder forms, which are compatible with life, can present with defective facial features such as hypotelorism and one nostril, but can also present with more distal manifestations such as polydactyly. Due to the location of the hypothalamus and pituitary gland as midline structures, their formation may be affected in HPE, resulting in hypopituitarism. Deficient $A D H$ production may occur in as many as $70 \%$ of affected patients [33]. Other variations of hypopituitarism presentation are isolated $\mathrm{GH}$ deficiency, MPHD or increasing manifestation of hormone deficiencies with age. Genetic mutations in the sonic hedgehog ( $\mathrm{SHH})$ gene are known to cause HPE and have also been linked to pituitary gland formation [34]. SHH is expressed in midline structures early in development, as well as controlling distal limb development. It is expressed in the ventral diencephalon and oral ectoderm, prior to formation of Rathke's pouch. SHH signalling, together with FGF8/10 (also known to cause HPE when mutated), regulate LHX3 signalling.

The GLI2 transcription factor, along with GLI1 and $\mathrm{GLI} 3$, is essential for mediating $\mathrm{SHH}$ signalling [35-37]. In mice, whilst GLI1 and GLI3 are unessential, GLI2 has been shown to be the major transcription factor required for pituitary development [38]. GLI2 is expressed in the same locations as $\mathrm{SHH}$ during pituitary development. Mutations in this gene phenotypically present with HPE-like features: polydactyly and hypopituitarism [35, 39]. GLI2 mutations, although often found in GHD with normal brain morphology [40], can cause anterior pituitary hypoplasia and an absent posterior pituitary. GLI2 mutants have been shown to affect the proliferation and specialization of cells in the pituitary gland, but not affect its formation. Therefore, the absence of the posterior pituitary is hypothesized to be due to its relationship with $\mathrm{SHH}$ [41].

\section{GLI3 and Pallister-Hall syndrome}

GLI3 autosomal dominant mutations causes Pallister-Hall syndrome [42]: a rare condition characterized by polydactyly, bifid epiglottis, hypothalamic hamartoma, pituitary dysfunction and an 
imperforate anus. The endocrine abnormalities can range from isolated GH deficiency to MPHD. De novo mutations are more severe in presentation than inherited mutations [43].

\section{FGF8 and FGFR1 in Kallmann syndrome and idiopathic hypogonadotrophic hypogonadism (IHH)}

Kallmann syndrome is one of a group of conditions known as hypogonadotropic hypogonadism $(\mathrm{HH})$, whereby gonadal development and functional activity is impaired by reduced gonadotropin secretion, associated with reduced or lack of sense of smell. Mutations in FGF8 and FGFR1 have been found in $10 \%$ of patients with Kallmann syndrome and $7 \%$ of those with idiopathic hypogonadotropic hypogonadism [44]. They are believed to control release of gonadotropin releasing hormone, which stimulates $\mathrm{LH}$ and FSH release from the pituitary gland. Clinically, $\mathrm{HH}$ presents with failure of pubertal onset with low levels of sex steroids and gonadotrophins. Milder phenotypes may include secondary amenorrhea, delay of puberty onset or adult onset of hypogonadotrophic hypogonadism. Although previously mutations in these genes were only thought to cause Kallmann syndrome/ $\mathrm{IHH}$, more recent studies have shown that mutations in these genes can also cause a wider phenotype of MPHD or SOD [45]. Mutations in several other genes are also impacted in the pathogenesis of Kallmann syndrome and $\mathrm{IHH}$ [46].

\section{Investigation of suspected hypopituitarism}

In a neonate with suspected hypopituitarism, biochemical evaluation of the hypothalamic-pituitary axis should be undertaken to evaluate for and define the extent of pituitary hormone deficiencies. As cortisol deficiency can be life-threatening, evaluation of ACTH deficiency by a short Synacthen test (sensitivity of $80 \%$ ) is essential. TSH deficiency can be identified by low serum free thyroxine (fT4) and normal/ low serum TSH. GH stimulation tests to diagnose GHD are undertaken after a year of age, although low GH levels during earlier spontaneous hypoglycaemia may suggest GHD. Hypogonadotrophic hypogonadism may be suspected in males with micropenis with or without bilateral undescended testes. Baseline low gonadotrophins with GnRH and HCG (in males) stimulation tests in infancy can help determine gonadotrophin deficiency. Diabetes insipidus is diagnosed by the presence of hypernatremia with raised plasma osmolality and concurrent low urine osmolality. MRI imaging of the brain and pituitary gland should be undertaken in any neonate with suspected hypopituitarism to evaluate the size of the anterior pituitary gland, the presence and location of posterior pituitary gland, the presence of midline (corpus callosum/ septum pellucidum) and other brain (such as HPE) abnormalities and the presence and size of the optic nerves.

Although several genetic causes of hypopituitarism have been identified by novel genetic technologies, the yield of genetic testing in hypopituitarism remains low. Detailed clinical and biochemical phenotyping along with MRI imaging of the pituitary gland may help identify those where genetic testing may be helpful. For example. PROP1 mutation needs to be considered in a patient with multiple pituitary hormone deficiency with an intact pituitary stalk and posterior pituitary [47]. In patients with septo-optic dysplasia, a HESX1 mutation should be investigated, although it has been recently shown that HESX1 mutations cause variable clinical features in patients and can also be seen in patients without septo-optic dysplasia [48]. Genetic testing is also likely to be beneficial in familial cases of hypopituitarism. Genetic analysis, however, is unlikely to be helpful in sporadic cases of hypopituitarism in Western European populations in the absence of specific MRI and extra-pituitary abnormalities [49, 50].

Management of an infant identified with hypopituitarism requires a multi-disciplinary team approach in a tertiary paediatric endocrinology centre and includes adequate replacement of hormone deficiencies and management of associated conditions and/or neurodevelopmental delay. Lifelong monitoring for adequacy of hormone replacement and evaluation of evolving hormone deficiencies is indicated. Genetic counselling should be offered to parents in whose infant a genetic cause has been identified.

\section{Conclusions}

Due to the serious complications associated with untreated disease, hypopituitarism should be considered in neonates presenting with hypoglycaemia, hypogonadism or unexplained jaundice. Many factors can cause congenital hypopituitarism: although rare, genetic causes of hypopituitarism are becoming better understood. The syndromes presenting with hypopituitarism associated with extra-pituitary abnormalities are more easily characterized and genetic causes more likely. For PROP1 it is important to consider the geographical origin of the patient as this mutation is more frequent in some ethnic groups [49]. MRI imaging of the brain and pituitary gland, along with hormonal profile and presence of specific extra-pituitary manifestations can help target specific genetic testing in patients with hypopituitarism. Similarly, this should be undertaken in infants with suspected hypopituitarism due to a positive family history. Despite the identification of an increased 
number of genetic causes of isolated or multiple pituitary deficiencies it should be appreciated that the etiology of most (80-90\%) congenital causes of hypopituitarism remain unsolved [12].

\section{Conflict of interest}

The authors declare no conflict of interest.

\section{References}

1. Pierce M, Madison L. Evaluation and initial management of hypopituitarism. Pediatr Rev 2016; 37: 370-5.

2. Mehta A, Hindmarsh PC, Dattani MT. An update on the biochemical diagnosis of congenital ACTH insufficiency. Clin Endocrinol 2005; 62: 307-14.

3. Medicine U. NL of. Combined pituitary hormone deficiency [Internet]. Genetics Home Reference. 2010 [cited 2018 Feb 13]. Available from: https://ghr.nlm.nih.gov/ condition/combined-pituitary-hormone-deficiency\#resources.

4. Sperling MA, Menon RK. Differential diagnosis and management of neonatal hypoglycemia. Pediatr Clin North Am 2004; 51: 703-23.

5. Kaufman FR, Costin G, Thomas DW, Sinatra FR, Roe TF, Neustein HB. Neonatal cholestasis and hypopituitarism. Arch Dis Child 1984; 59: 787-9.

6. Ellaway CJ, Silink M, Cowell CT, et al. Cholestatic jaundice and congenital hypopituitarism. J Paediatr Child Health 1995; 31: 51-3.

7. Karnsakul W, Sawathiparnich P, Nimkarn S, Likitmaskul S, Santiprabhob J, Aanpreung P. Anterior pituitary hormone effects on hepatic functions in infants with congenital hypopituitarism. Ann Hepatol 2007; 6: 97-103.

8. Webb EA, Dattani MT. Understanding hypopituitarism. Paediatr Child Health 2011; 21: 289-94.

9. Reynaud R, Gueydan M, Saveanu A, et al. Genetic screening of combined pituitary hormone deficiency: experience in 195 patients. J Clin Endocrinol Metab 2006; 91: 3329-36.

10. Mody S, Brown MR, Parks JS. The spectrum of hypopituitarism caused by PROP1 mutations. Clin Endocrinol Metab 2002; 16: 421-31.

11. Alatzoglou KS, Dattani MT. Genetic forms of hypopituitarism and their manifestation in the neonatal period. Early Hum Dev 2009; 85: 705-12.

12. Castinetti F, Reynaud R, Quentien MH, et al. Combined pituitary hormone deficiency: current and future status. J Endocrinol Invest 2015; 38: 1-12.

13. Turton J, Reynaud R, Mehta A, et al. Novel mutations within the POU1F1 gene associated with variable combined pituitary hormone deficiency. J Clin Endocrinol Metab 2005; 90: 4762-70.

14. Kelberman D, Dattani MT. Hypothalamic and pituitary development: novel insights into the aetiology. Eur J Endocrinol 2007; 157: S3-14

15. Lee NC, Tsai WY, Peng SF, Tung YC, Chien YH, Hwu WL. Congenital hypopituitarism due to POU1F1 gene mutation. J Formos Med Assoc 2011; 110: 58-61.

16. Takagi M, Kamasaki H, Yagi H, Fukuzawa R, Narumi $S$, Hasegawa T. A novel heterozygous intronic mutation in POU1F1 is associated with combined pituitary hormone deficiency. Endocr J 2017; 64: 229-34.

17. McLennan K, Jeske Y, Cotterill A, et al. Combined pituitary hormone deficiency in Australian children: clinical and genetic correlates. Clin Endocrinol 2003; 58: 785-94.
18. Tajima T, Hattori T, Nakajima T, Okuhara K, Tsubaki J, Fujieda K. A novel missense mutation (P366T) of the LHX4 gene causes severe combined pituitary hormone deficiency with pituitary hypoplasia, ectopic posterior lobe and a poorly developed sella turcica. Endocr J 2007; 54: 637-41.

19. Rajab A, Kelberman D, De Castro SCP, et al. Novel mutations in LHX3 are associated with hypopituitarism and sensorineural hearing loss. Hum Mol Genet 2008; 17 2150-9.

20. Ramzan K, Bin-Abbas B, Al-Jomaa L, Allam R, Al-Owain M, Imtiaz F. Two novel LHX3 mutations in patients with combined pituitary hormone deficiency including cervical rigidity and sensorineural hearing loss. BMC Endocr Disord 2017; 17: 17

21. Jullien N, Romanet $P$, Philippon $M$, et al. Heterozygous LHX3 mutations may lead to a mild phenotype of combined pituitary hormone deficiency. Eur J Hum Genet 2019; 27: 216-25.

22. Carreno G, Apps JR, Lodge EJ, et al. Hypothalmic sonic hedgehog is required for cell specification and proliferation of LHX3/LHX4 pituitary embryonic precursors. Development 2017; 144: 3289-302.

23. Machinis K, Pantel J, Netchine I, et al. Syndromic short stature in patients with a germline mutation in the LIM homeobox LHX4. Am J Hum Genet 2001; 69: 961-8.

24. Castinetti F, Saveanu A, Reynaud R, et al. A novel dysfunctional LHX4 mutation with high phenotypical variability in patients with hypopituitarism. J Clin Endocrinol Metab 2008; 93: 2790-9.

25. Pfaeffle RW, Hunter CS, Savage JJ, et al. Three novel missense mutations within the LHX4 gene are associated with variable pituitary hormone deficiencies. J Clin Endocrinol Metab 2008; 93: 1062-71.

26. Cohen E, Maghnie M, Collot N, et al. Contribution of LHX4 mutations to pituitary deficits in a cohort of 417 unrelated patients. J Clin Endocrinol Metab 2017; 102: 290-301.

27. Kelberman D, Dattani MT. Septo-optic dysplasia - novel insights into the aetiology. Hormone Res 2008; 69: 257-65.

28. Corneli G, Vivenza D, Prodam F, et al. Heterozygous mutation of HESX1 causing hypopituitarism and multiple anatomical malformations without features of septooptic dysplasia. J Endocrinol Invest 2008; 31: 689-93.

29. McNay DEG, Turton JP, Kelberman D, et al. HESX1 mutations are an uncommon cause of septooptic dysplasia and hypopituitarism. J Clin Endocrinol Metab 2007; 92: 691-7.

30. Ahmad T, Garcia-Filion P, Borchert M, Kaufman F, Burkett L, Geffner M. Endocrinological and auxological abnormalities in young children with optic nerve hypoplasia: a prospective study. J Pediatr 2006; 148: 78-84.

31. Thomas PQ, Dattani MT, Brickman JM, et al. Heterozygous HESX1 mutations associated with isolated congenital pituitary hypoplasia and septo-optic dysplasia. Hum Mol Genet 2001; 10: 39-45.

32. Macchiaroli A, Kelberman D, Auriemma RS, et al. A novel heterozygous SOX2 mutation causing congenital bilateral anophthalmia, hypogonadotropic hypogonadism and growth hormone deficiency Gene 2014; 534: 282-5.

33. Hahn JS, Hahn SM, Kammann H, et al. Endocrine disorders associated with holoprosencephaly. J Ped Endocrinol Metab 2005; 18: 935-41.

34. Treier M, O'Connell S, Gleiberman A, et al. Hedgehog signaling is required for pituitary gland development. Development 2001; 128: 377-86.

35. Roessler E, Du YZ, Mullor JL, et al. Loss-of-function mutations in the human GLI2 gene are associated with pi- 
tuitary anomalies and holoprosencephaly-like features. Proc Natl Acad Sci 2003; 100: 13424-9.

36. Hardcastle Z, Mo R, Hui CC, Sharpe PT. The Shh signalling pathway in tooth development: defects in Gli2 and Gli3 mutants. Development 1998; 125: 2803-11.

37. Arnhold IJP, Franca MM, Carvalho LR, Mendonca BB, Jorge AA. Role of GLI2 in hypopituitarism phenotype. J Mol Endocrinol 2015; 54: R141-50.

38. Park HL, Bai C, Platt KA, et al. Mouse Gli1 mutants are viable but have defects in $\mathrm{SHH}$ signaling in combination with a Gli2 mutation. Development 2000; 127: 1593-605.

39. Bear KA, Solomon BD, Antonini S, et al. Pathogenic mutations in GLI2 cause a specific phenotype that is distinct from holoprosencephaly. J Med Genet 2014; 51: 413-8.

40. Stieg MR, Renner U, Stalla GK, Kopczak A. Advances in understanding hypopituitarism. F1000Res 2017; 6: 178.

41. Wang Y, Martin JF, Bai CB. Direct and indirect requirements of Shh/Gli signaling in early pituitary development. Dev Biol 2010; 348: 199-209.

42. Kang S, Graham JM, Olney AH, Biesecker LG. GLI3 frameshift mutations cause autosomal dominant Pallister-Hall syndrome. Nat Genet 1997; 15: 266-8.

43. Biesecker LG. Pallister-Hall Syndrome [Internet]. GeneReviews ${ }^{\circledR} .2017$ [cited 2018 Feb 19]. Available from: https://www.ncbi.nlm.nih.gov/books/NBK1465/.

44. Raivio T, Sidis Y, Plummer L, et al. Impaired fibroblast growth factor receptor 1 signaling as a cause of normosmic idiopathic hypogonadotropic hypogonadism. J Clin Endocrinol Metab 2009; 94: 4380-90.

45. Raivio T, Avbelj M, McCabe MJ, et al. Genetic overlap in Kallmann syndrome, combined pituitary hormone deficiency and septo-optic dysplasia. J Clin Endocrinol Metal 2012; 97: E694-9.

46. Stamou MI, Georgopoulos N. Kallmann syndrome: phenotype and genotype of hypogonadotropic hypogonadism. Metabolism 2018; 86: 124-34.

47. Tkacenko N, Lasiene D, Jakstiene S, Basevicius A, Verkauskiene R. Evaluation of pituitary imaging in patients with prop-1 gene mutation. Medicina 2009; 45: 693-8.

48. Fang $\mathrm{Q}$, Benedetti $A F, M a$ Q et al. HESX1 mutations in patients with congenital hypopituitarism: variable phenotypes with the same genotype. Clin Endocrinol 2016; 85: 408-14

49. Crisafulli G, Aversa T, Zirilli G, De Luca F, Gallizzi R, Wasniewska M. Congenital hypopituitarism: how to select the patients for genetic analyses. Ital J Pediatr 2018; 44: 47.

50. De Rienzo F, Mellone S, Bellone S, et al. Frequency of genetic defects in combined pituitary hormone deficiency: a systematic review and analysis of a multicentre Italian cohort. Clin Endocrinol 2015; 83: 849-60. 